\title{
Discriminative stimulus effects of pregnanolone in rhesus monkeys
}

\author{
Lisa R. Gerak and Charles P. France \\ Departments of Pharmacology (LRG and CPF) and Psychiatry (CPF), The University of Texas \\ Health Science Center at San Antonio, 7703 Floyd Curl Drive, San Antonio, TX, USA 78229-3900
}

\begin{abstract}
Rationale-Neuroactive steroids and benzodiazepines can positively modulate GABA by acting at distinct binding sites on synaptic $\mathrm{GABA}_{\mathrm{A}}$ receptors. Although these receptors are thought to mediate the behavioral effects of both benzodiazepines and neuroactive steroids, other receptors (e.g., extrasynaptic $\mathrm{GABA}_{\mathrm{A}}$, NMDA, $\sigma_{1}$, or $5-\mathrm{HT}_{3}$ receptors) might contribute to the effects of neuroactive steroids, resulting in differences among positive modulators.
\end{abstract}

Objective-The current study established the neuroactive steroid pregnanolone as a discriminative stimulus to determine whether actions in addition to positive modulation of synaptic $\mathrm{GABA}_{\mathrm{A}}$ receptors might contribute to its discriminative stimulus effects.

Methods-Four rhesus monkeys discriminated $5.6 \mathrm{mg} / \mathrm{kg}$ pregnanolone while responding under a fixed-ratio 10 schedule of stimulus-shock termination.

Results-Positive modulators acting at benzodiazepine, barbiturate, or neuroactive steroid sites produced $\geq 80 \%$ pregnanolone-lever responding, whereas drugs acting primarily at receptors other than synaptic $\mathrm{GABA}_{\mathrm{A}}$ receptors, such as extrasynaptic $\mathrm{GABA}_{\mathrm{A}}, \mathrm{NMDA}, \sigma_{1}$, and 5- $\mathrm{HT}_{3}$ receptors, produced vehicle-lever responding. Flumazenil antagonized the benzodiazepines midazolam and flunitrazepam, with Schild analyses yielding slopes that did not deviate from unity and $\mathrm{pA}_{2}$ values of 7.39 and 7.32, respectively. Flumazenil did not alter the discriminative stimulus effects of pregnanolone.

Conclusion-While these results do not exclude the possibility that pregnanolone acts at receptors other than synaptic $\mathrm{GABA}_{\mathrm{A}}$ receptors, they indicate a primary if not exclusive role of synaptic $\mathrm{GABA}_{\mathrm{A}}$ receptors in its discriminative stimulus effects. Reported differences in the chronic effects of benzodiazepines and neuroactive steroids are not due to differences in their actions at synaptic $\mathrm{GABA}_{\mathrm{A}}$ receptors.

\section{Keywords}

pregnanolone; benzodiazepines; drug discrimination; rhesus monkeys

Drugs acting at $\mathrm{GABA}_{\mathrm{A}}$ receptors have been used effectively to treat several disorders, such as anxiety and insomnia. Their clinical use is often limited by adverse effects, and one common strategy for reducing unwanted effects without altering therapeutic effects is to target the subset of receptors mediating the desired effect. This approach might be particularly useful for drugs acting at $\mathrm{GABA}_{\mathrm{A}}$ receptors due to their diversity. The $\mathrm{GABA}_{\mathrm{A}}$ receptor complex comprises 5 protein subunits, and there are multiple subtypes of each subunit; while thousands of different $\mathrm{GABA}_{\mathrm{A}}$ receptors are possible, fewer than 20 exist in mammalian brain (McKernan and Whiting 1996; Wafford 2005; Korpi and Sinkkonen 
2006). In addition to the GABA binding site, $\mathrm{GABA}_{\mathrm{A}}$ receptors have several modulatory sites, and the presence or absence of particular modulatory sites depends on subunit composition. Most therapeutics whose effects are mediated by $\mathrm{GABA}_{\mathrm{A}}$ receptors act at modulatory sites, including benzodiazepines and barbiturates which are positive $\mathrm{GABA}_{\mathrm{A}}$ modulators acting at distinct sites. Another therapeutic target on $\mathrm{GABA}_{\mathrm{A}}$ receptors is the neuroactive steroid site. Positive modulators acting at neuroactive steroid sites produce effects similar to those produced by benzodiazepines, including anxiolytic (Wieland et al. 1997), sedative (Lancel 1999; Vanover et al. 1999) and anticonvulsant effects (Kokate et al. 1994; Reddy and Rogawski 2001). While similar, the effects of positive modulators acting at different sites are not identical. For example, less tolerance and dependence develop with neuroactive steroids, as compared to benzodiazepines (Eppolito and Gerak 2010; Kokate et al. 1998; Reddy and Rogawski 2000). Thus, neuroactive steroids might retain the therapeutic effects of benzodiazepines while limiting their adverse effects, particularly tolerance and dependence.

Several factors could account for differences in the behavioral effects of benzodiazepines and neuroactive steroids. One possibility is the subunit composition of $\mathrm{GABA}_{\mathrm{A}}$ receptors, which determines the presence of particular binding sites and selectivity for drugs acting at those sites. Benzodiazepine sites exist only on $\mathrm{GABA}_{\mathrm{A}}$ receptors that contain two a subunits ( $a 1, a 2, a 3$, or $a 5)$, two $\beta$ subunits, and one $\gamma 2$ subunit (Olsen and Sieghart 2009) whereas neuroactive steroid sites are thought to be present on most $\mathrm{GABA}_{\mathrm{A}}$ receptors (Hosie et al. 2006). $\mathrm{GABA}_{\mathrm{A}}$ receptors containing $\alpha 1 \beta \gamma 2$ are the most abundant in mammalian brain, can interact with benzodiazepines and neuroactive steroids, and are located in synapses (Olsen and Sieghart 2009; Olsen et al. 2007). Other $\mathrm{GABA}_{\mathrm{A}}$ receptors contain a4 or a6 along with $\delta$ subunits; these receptors are extrasynaptic and can be modulated by neuroactive steroids but not benzodiazepines, which could contribute to differences in their behavioral effects. Another difference between benzodiazepines and neuroactive steroids is that benzodiazepines primarily act at $\mathrm{GABA}_{\mathrm{A}}$ receptors whereas neuroactive steroids might act at other receptors in addition to their actions at $\mathrm{GABA}_{\mathrm{A}}$ receptors, including $\mathrm{N}$-methyl-Daspartate (NMDA), 5-hydroxytryptamine (5- $\left.\mathrm{HT}_{3}\right)$, and sigma $\left(\sigma_{1}\right)$ receptors (Maurice et al. 2001; Rupprecht et al. 2001; Dubrovsky 2005).

Although differences in behavioral effects of benzodiazepines and neuroactive steroids are primarily observed during chronic treatment, their effects are not always identical following acute administration, and differences in the acute behavioral effects have been detected using drug discrimination. In general, positive modulators produce drug-lever responding regardless of whether the training drug acts at benzodiazepine, barbiturate, or neuroactive steroid binding sites e.g., (de la Garza and Johanson 1987; Ator et al. 1993; Rowlett et al. 1999; McMahon et al. 2001; Engel et al. 2001). Collectively, those results suggest that the pharmacology of neuroactive steroids largely overlaps with that of benzodiazepines and barbiturates; however, differences in discriminative stimulus effects imply that mechanisms contributing to these effects are not identical for benzodiazepines and neuroactive steroids. For example, in rats discriminating the benzodiazepine lorazepam, neuroactive steroids do not produce lorazepam-lever responding (Ator et al. 1993). Similarly, in pigeons or rhesus monkeys discriminating the benzodiazepine midazolam, neuroactive steroids produce midazolam-lever responding in some, but not all, individuals (Evans and Johanson 1989; Gerak et al. 2008a), suggesting that the discriminative stimulus effects of benzodiazepines and neuroactive steroids are not identical. It is interesting to note that in rats discriminating midazolam, neuroactive steroids produce $\geq 80 \%$ midazolam-lever responding in all subjects (Bai and Gerak 2011). Barbiturates also seem to be more likely to produce midazolam-lever responding in rats (Ator 1990; 1999; Garcha et al. 1985; Woudenberg and Slangen 1989; but see also Bai and Gerak 2011), as compared to squirrel monkeys (Spealman 1985), baboons (Ator 2003), rhesus monkeys (Gerak et al. 2008a), and pigeons (Evans and Johanson 1989). 
Taken together, these results indicate that effects obtained with positive $\mathrm{GABA}_{\mathrm{A}}$ modulators acting at different sites are not identical and effects obtained in one species do not necessarily predict effects obtained in others.

The neuroactive steroid pregnanolone has been established as a discriminative stimulus in rodents. Benzodiazepines produce $\geq 80 \%$ pregnanolone-lever responding in rats (Vanover 1997; 2000; Engel et al. 2001; Gerak et al. 2008b) or mice (Shannon et al. 2005a; b); however, it appears as though differences among positive $\mathrm{GABA}_{\mathrm{A}}$ modulators are not as likely to be detected in rodents, as compared to other species. Thus, it is important to establish a pregnanolone discriminative stimulus in other species to examine the generality of results obtained in rodents.

The current study established pregnanolone as a discriminative stimulus in rhesus monkeys and compared results to those reported in monkeys discriminating midazolam to examine whether the effects of pregnanolone are due to actions at synaptic $\mathrm{GABA}_{\mathrm{A}}$ receptors or whether other mechanisms play a role. The involvement of $\mathrm{GABA}_{\mathrm{A}}$ receptors in the discriminative stimulus effects of pregnanolone was examined by determining whether positive modulators acting at synaptic $\mathrm{GABA}_{\mathrm{A}}$ receptors as well as drugs acting at other receptors, including extrasynaptic $\mathrm{GABA}_{\mathrm{A}}$ (gaboxadol), NMDA (ketamine, dizocilpine), $\sigma_{1}$ (nallylnormetazocine), and 5- $\mathrm{HT}_{3}$ [1-(m-chlorophenyl)-biguanide (CPBG)] receptors, produced effects similar to those of pregnanolone. Similarities in the discriminative stimulus effects of benzodiazepines and neuroactive steroids would support a predominant role of synaptic $\mathrm{GABA}_{\mathrm{A}}$ receptors, and this hypothesis was tested further using drug combination studies with flumazenil, which acts at benzodiazepine sites and attenuates the effects of benzodiazepines. In monkeys discriminating midazolam, flumazenil shifted dose-effect curves rightward (Lelas et al. 1999; 2000; Gerak and France 2012); in the same monkeys, flumazenil enhanced the midazolam-like effects of neuroactive steroids, shifting dose-effect curves leftward (McMahon and France 2005; Gerak and France 2011; 2012), and reflecting the limited positive modulatory actions of flumazenil at benzodiazepine sites on $\mathrm{GABA}_{\mathrm{A}}$ receptors (Dantzer and Pério 1982). To the extent that the same synaptic $\mathrm{GABA}_{\mathrm{A}}$ receptors that mediate the effects of benzodiazepines in monkeys discriminating midazolam also mediate the effects of neuroactive steroids in monkeys discriminating pregnanolone, then effects obtained in the current study should be similar to those reported in monkeys discriminating midazolam.

\section{Methods}

\section{Subjects}

Four experimentally naïve male rhesus monkeys were between 4.5 and 5.75 years old when the experiment began. They were housed individually on a $14 \mathrm{hr}$ light and $10 \mathrm{hr}$ dark cycle with free access to water in their home cage. Monkeys received primate chow (Harlan Teklad, High Protein Monkey Diet, Madison, WI), fresh fruit and peanuts daily. Over the course of the study, which lasted at least 2 years, their weights increased from $4.5-6.9 \mathrm{~kg}$ to $8.5-11 \mathrm{~kg}$. Monkeys were maintained in accordance with the Institutional Animal Care and Use Committee, The University of Texas Health Science Center at San Antonio, and with the 2011 Guide for the Care and Use of Laboratory Animals (Institute of Laboratory Animal Resources 2011).

\section{Apparatus}

During experimental sessions, monkeys were seated in chairs (Primate Products, Miami, FL), which were placed in ventilated, sound-attenuating chambers. White noise was present in each chamber. Two stimulus lights and two levers were mounted on the chamber wall 
within easy reach of seated monkeys. The feet of the monkeys were placed in shoes mounted on the front of the chair. Shoes contained brass electrodes to which brief ( 250 msec, $3 \mathrm{~mA}$ ) electric shock could be delivered from an a.c. shock generator located outside of chambers. Experimental events were controlled and data were recorded by a computer that used MED-PC IV software (MED Associates, Inc., St. Albans, VT) and was connected to the chambers by a commercially available interface (MED Associates, Inc., St. Albans, VT).

\section{Procedure}

Four monkeys discriminated $5.6 \mathrm{mg} / \mathrm{kg}$ pregnanolone while responding under a fixed-ratio 10 schedule of stimulus-shock termination. Because there were no previous studies in which monkeys discriminated pregnanolone, the initial dose and temporal conditions used to establish stimulus control were similar but not identical across monkeys, although eventually conditions were the same for all monkeys. For example, a training dose of 3.2 $\mathrm{mg} / \mathrm{kg}$ was used initially for 2 monkeys; after 100 training sessions, adequate stimulus control had been established only in one monkey. Consequently, the training dose was increased to $5.6 \mathrm{mg} / \mathrm{kg}$ in both monkeys and training began with $5.6 \mathrm{mg} / \mathrm{kg}$ in the 2 monkeys that were trained later. These slight variations in training did not appear to alter the pregnanolone discriminative stimulus, as results were indistinguishable across subjects.

Sessions were conducted 7 days per week, lasted up to $2 \mathrm{hr}$, and were divided into 15-min cycles, beginning with 10-min timeout periods, when chambers were dark and responding had no programmed consequence, and ending with 5-min response periods, when red stimulus lights were illuminated and the schedule of stimulus-shock termination was in effect. In the presence of red lights, 10 consecutive responses on the lever designated correct by an injection administered during the first minute of the cycle extinguished lights and postponed the shock schedule for $30 \mathrm{sec}$. Responses on the incorrect lever reset the response requirement on the correct lever. The lever designated correct after administration of pregnanolone was counterbalanced across monkeys. When the response requirement was not satisfied within $15 \mathrm{sec}$ of illumination of lights, brief electric shock was delivered and continued to be delivered every $15 \mathrm{sec}$ until the response requirement was satisfied or the cycle ended either because four shocks were delivered or 15 min elapsed since the beginning of the cycle.

For some training sessions, $5.6 \mathrm{mg} / \mathrm{kg}$ pregnanolone was given in the first cycle followed by a sham injection given in the next cycle; responding on the pregnanolone lever postponed shock during both cycles because the discriminative stimulus effects of $5.6 \mathrm{mg} / \mathrm{kg}$ pregnanolone last at least $2 \mathrm{hr}$ in rhesus monkeys (unpublished observation). Other training sessions comprised 2-8 cycles in which vehicle or sham injections were administered and responding on the vehicle lever postposed shock during all cycles. Still other training sessions began with up to 6 cycles in which vehicle or sham was given, followed by a cycle in which $5.6 \mathrm{mg} / \mathrm{kg}$ pregnanolone was given and one subsequent sham cycle. Stimulus control was considered adequate to begin testing when the following criteria were satisfied for 5 consecutive or 6 of 7 training sessions: $\searrow 0 \%$ responding on the correct lever and fewer than 10 responses on the incorrect lever prior to completion of the first fixed ratio on the correct lever. Thereafter, test sessions were conducted every third day as long as the testing criteria were satisfied during intervening training sessions; otherwise training continued until the criteria were satisfied for 2 consecutive sessions.

Test sessions were identical to training sessions except that 10 consecutive responses on either lever postponed shock and test compounds were administered. To determine whether the discriminative stimulus effects of rugs from different pharmacological classes were similar to those of pregnanolone, dose-effect curves were determined using an acute 
(gaboxadol and dizocilpine) or cumulative (all other drugs) dosing procedure. For cumulative dosing, vehicle was given on the first cycle and a test compound was given beginning on the second cycle with the cumulative dose increasing by $1 / 4 \log$ unit per cycle. Dosing continued until monkeys responded $₫ 80 \%$ on the pregnanolone lever, response rates decreased sufficiently to result in the delivery of shock, or solubility of drug precluded further increases in dose. The cumulative dosing procedure could not be used with gaboxadol and dizocilpine due to their slow onset of action; consequently, a single dose was given on the first cycle of a session comprising 6 cycles with sham injections given during each cycle after the first. Different doses were given during separate test sessions, beginning with an ineffective dose and increasing in $1 / 4 \log$ unit increments up to a dose that markedly decreased responding in at least 2 monkeys. At large doses, response rates were decreased sufficiently to result in the delivery of shock; when shock was delivered in two consecutive cycles, the session was stopped and the effects of drug at later time points were not determined. The ability of flumazenil to alter the discriminative stimulus effects of benzodiazepines and neuroactive steroids was determined by giving a single dose of flumazenil $(0.01-0.32 \mathrm{mg} / \mathrm{kg})$ on the first cycle and cumulative doses of a test compound on subsequent cycles, up to doses that produced $\$ 80 \%$ responding on the pregnanolone lever.

\section{Drugs}

Pregnanolone (5 $\beta$-pregnan-3a-ol-20-one; Research Technology Branch, National Institute on Drug Abuse, Rockville, MD) and allopregnanolone (5a-pregnan-3a-ol-20-one; Bujno Synthesis, Warsaw, Poland) were dissolved in $45 \%$ (w/v) 2-hydroxypropyl- $\beta$-cyclodextrin. Midazolam hydrochloride (Hospira Inc, Lake Forest, IL) and ketamine hydrochloride (Butler Animal Health Supply, Galway, Ireland) were purchased as commercially prepared solutions and diluted with sterile water. Flunitrazepam (Research Technology Branch, National Institute on Drug Abuse, Rockville, MD) was dissolved in a vehicle containing $20 \%$ emulphor, $10 \%$ ethanol and $70 \%$ sterile water. Pentobarbital sodium, gaboxadol hydrochloride, 1-(m-chlorophenyl)-biguanide hydrochloride (CPBG), dizocilpine hydrogen maleate, and chlorpromazine hydrochloride (Sigma-Aldrich Co., St. Louis, MO), along with n-allylnormetazocine hydrochloride (Research Technology Branch, National Institute on Drug Abuse, Rockville, MD), were dissolved in sterile water. Haloperidol (Sigma-Aldrich Co., St. Louis, MO) was dissolved in water containing a small amount of lactic acid; once dissolved, the $\mathrm{pH}$ of the solution was increased to $\geq 5$ with $5 \mathrm{M} \mathrm{NaOH}$. Flumazenil (Enzo Life Sciences, Farmingdale, NY) was dissolved in a vehicle comprising 10\% ethanol, $40 \%$ propylene glycol, and 50\% sterile water. Doses are expressed in terms of the forms listed above in $\mathrm{mg} / \mathrm{kg}$ body weight. Drugs were administered s.c. in volumes ranging from $0.3-2$ $\mathrm{ml}$.

\section{Data Analyses}

Discrimination data, expressed as a percentage of total responses emitted on the pregnanolone lever, and response rates, expressed as responses/sec, were averaged across monkeys ( \pm 1 SEM) and plotted as a function of dose or time. Mean control response rates were obtained by averaging rates across cycles for training sessions in which monkeys received only vehicle or sham injections and satisfied the testing criteria during each cycle. Control rates represent the average of the means for 5 training sessions. During test sessions, cumulative dosing for an individual monkey stopped when that individual responded at least $80 \%$ on the pregnanolone lever; in cases where larger doses were studied in other monkeys, a value of $100 \%$ pregnanolone-lever responding was entered for that individual at those larger doses and used in the group analyses (Gerak and France 2012). With the exception of CPBG, which was determined once in 3 monkeys, all tests were determined twice in 4 monkeys; data were averaged for individuals before the group mean was obtained. 
To determine whether flumazenil altered the discriminative stimulus effects of benzodiazepines or neuroactive steroids, $\mathrm{ED}_{50}$ values obtained in the presence and absence of flumazenil were compared. First, straight lines were fitted to individual dose-effect curves for each monkey using one dose that produced not more than $25 \%$ responding on the drug lever, one dose that produced at least $75 \%$ responding on the drug lever, and all doses in between. Then, $\mathrm{ED}_{50}$ values were calculated using linear regression or interpolation, depending on the number of data points available. For individuals, potency ratios were obtained by dividing $\mathrm{ED}_{50}$ values determined with flumazenil by $\mathrm{ED}_{50}$ values determined without flumazenil. A significant change in the potency of a benzodiazepine or neuroactive steroid was detected when the $95 \%$ confidence intervals of the potency ratios averaged among monkeys did not include 1 . When flumazenil antagonized the discriminative stimulus effects of a positive modulator, dose ratios were also used to construct Schild plots using the method of Arunlakshana and Schild (1959) and GraphPad Prism version 5.01 for Windows (GraphPad Software, San Diego, CA). For individuals, log (dose ratio-1) was calculated; the mean among monkeys was then plotted as a function of flumazenil dose $(-\log [\mathrm{mol} / \mathrm{kg}])$ and straight lines were fitted. An F-ratio test was used to compare Schild plots; if the calculated $\mathrm{F}$ value was not significant, then the data were best fit when slopes were constrained to unity, rather than being allowed to vary, and apparent $\mathrm{pA}_{2}$ values were compared using an F-ratio test (Kenakin 1993; Koek et al. 2000). When slopes were not constrained, apparent $\mathrm{pA}_{2}$ values $(95 \% \mathrm{CI})$ were determined using linear regression. Significance was set at $\mathrm{P}<0.05$.

\section{Results}

On average, 174 sessions (range: 112-234 sessions, beginning with the first session in which monkeys received pregnanolone) were required for monkeys to satisfy the testing criteria. After stimulus control was established, the mean response rate ( \pm 1 SEM) was $2.42 \pm 0.41$ responses/sec in vehicle training sessions and $2.56 \pm 0.16$ responses/s in pregnanolone (5.6 $\mathrm{mg} / \mathrm{kg}$ ) training sessions; rates were not significantly changed over the course of the experiment (data not shown). During test sessions, administration of vehicle resulted in responding on the vehicle lever and no change in rates (points above V, Figure 1). Pregnanolone dose dependently increased responding on the pregnanolone lever with 3.2 $\mathrm{mg} / \mathrm{kg}$ producing, on average, $98 \%$ drug-lever responding (circles, upper panel, Figure 1). The mean $\mathrm{ED}_{50}$ value (mean \pm 1 S.E.M.) was $1.57 \pm 0.27 \mathrm{mg} / \mathrm{kg}$. Pregnanolone $(3.2 \mathrm{mg} / \mathrm{kg})$ modestly increased response rates.

Other positive $\mathrm{GABA}_{\mathrm{A}}$ modulators produced $280 \%$ pregnanolone-lever responding (upper panel, Figure 1). The benzodiazepines midazolam and flunitrazepam were the most potent with $\mathrm{ED}_{50}$ values for discriminative stimulus effects of $0.28 \pm 0.05 \mathrm{mg} / \mathrm{kg}$ and $0.11 \pm 0.01$ $\mathrm{mg} / \mathrm{kg}$, respectively. The neuroactive steroid allopregnanolone $\left(\mathrm{ED}_{50}=0.82 \pm 0.16 \mathrm{mg} / \mathrm{kg}\right.$ ) was 2 -fold more potent than pregnanolone whereas the barbiturate pentobarbital $\left(\mathrm{ED}_{50}=\right.$ $6.98 \pm 0.52 \mathrm{mg} / \mathrm{kg}$ ) was the least potent. These positive modulators did not markedly alter response rates (lower panel, Figure 1).

The pharmacological selectivity of the pregnanolone discriminative stimulus was further tested with drugs whose primary mechanisms of action are not at synaptic $\mathrm{GABA}_{\mathrm{A}}$ receptors. The dopamine receptor antagonists haloperidol and chlorpromazine, the NMDA receptor antagonist ketamine, and the $\sigma$ receptor agonist n-allylnormetazocine produced predominantly vehicle-lever responding (upper panel, Figure 2) up to doses that decreased response rates (lower panel, Figure 2). The 5-HT 3 receptor agonist CPBG also produced predominantly vehicle-lever responding, although response rates were not decreased up to $56 \mathrm{mg} / \mathrm{kg}$, the largest dose that could be studied due to solubility. In addition, neither the extrasynaptic $\mathrm{GABA}_{\mathrm{A}}$ receptor agonist gaboxadol nor the NMDA receptor antagonist 
dizocilpine produced $>20 \%$ pregnanolone-lever responding at any dose (upper panel, Figure 3 ), and the largest doses of gaboxadol and dizocilpine eliminated responding in 2 and 4 monkeys, respectively (lower panels, Figure 3).

Flumazenil antagonized the discriminative stimulus effects of midazolam and flunitrazepam (Figure 4). A small dose of flumazenil $(0.0178 \mathrm{mg} / \mathrm{kg})$ did not significantly change the potency of midazolam; the mean potency ratio for midazolam $(95 \% \mathrm{CI})$ was $2.63(0.84$, 4.42). Larger doses of flumazenil significantly attenuated the discriminative stimulus effects of both midazolam and flunitrazepam. The mean potency ratio obtained for midazolam in combination with $0.032 \mathrm{mg} / \mathrm{kg}$ of flumazenil was $3.90(2.39,5.40)$ and the mean potency ratio for flunitrazepam with the same dose of flumazenil was 3.09 (1.97, 4.21). Straight lines fitted to Schild plots (Figure 5) indicated that slopes $[F(1,24)=0.14$, n.s.] and intercepts $[\mathrm{F}(1,26)=1.373$, n.s.] were not significantly different, and the common slope was not different from unity $[\mathrm{F}(1,25)=0.252$, n.s.]. Thus, the data were best fit by the simplest model with a common slope and a common intercept. When the common slope was constrained to unity, the apparent $\mathrm{pA}_{2}$ value was 7.36. When analyzed independently, the unconstrained slope of each Schild plot was not significantly different from unity yielding apparent $\mathrm{pA}_{2}$ values that were also not significantly different (Table 1).

A dose of $0.1 \mathrm{mg} / \mathrm{kg}$ of flumazenil, which shifted the midazolam and flunitrazepam doseeffect curves significantly rightward (Figures 4 and 5), did not alter the discriminative stimulus effects of pregnanolone (Figure 6). A mean potency ratio of $1.08(0.63,1.53)$ was obtained when pregnanolone was studied with $0.1 \mathrm{mg} / \mathrm{kg}$ of flumazenil. Despite a trend for a leftward shift in the pregnanolone dose-effect curve, a larger dose of flumazenil $(0.32 \mathrm{mg} /$ $\mathrm{kg}$ ) did not significantly alter the dose-effect curve of either pregnanolone (mean potency ratio $=0.89[0.46,1.31]$ ) or allopregnanolone (mean potency ratio $=1.00[0.51,1.48]$; Figure $6)$.

\section{Discussion}

Benzodiazepines and neuroactive steroids can positively modulate GABA, although they act at distinct sites on synaptic $\mathrm{GABA}_{\mathrm{A}}$ receptors. Both increase $\mathrm{Cl}^{-}$influx and their acute behavioral effects are similar e.g., (Ator et al. 1993; Engel et al. 2001; McMahon and France 2005; Bai and Gerak 2011), although not identical (e.g., development of tolerance to benzodiazepines and not neuroactive steroids; Gonsalves and Gallagher 1987; Löscher et al. 1996; Kokate et al. 1998; Reddy and Rogawski 2000; McMahon and France 2002a; b). The current study established pregnanolone as a discriminative stimulus in monkeys to determine whether actions at receptors other than GABAA receptors might contribute to the discriminative stimulus effects of pregnanolone, as has been shown previously in rats. Although the current data do not exclude the possibility that pregnanolone has actions at receptors other than synaptic $\mathrm{GABA}_{\mathrm{A}}$ receptors, other receptors do not play a role in the effects of pregnanolone when it is trained as a discriminative stimulus in rhesus monkeys.

Positive $\mathrm{GABA}_{\mathrm{A}}$ modulators acting at different sites on $\mathrm{GABA}_{\mathrm{A}}$ receptors produced pregnanolone-lever responding in monkeys, despite differences in pharmacokinetics and solubility. Because benzodiazepines act at synaptic $\mathrm{GABA}_{\mathrm{A}}$ receptors, and not at either extrasynaptic $\mathrm{GABA}_{\mathrm{A}}$ or other (non-GABA) receptors, their substitution for pregnanolone suggests that synaptic $\mathrm{GABA}_{\mathrm{A}}$ receptors mediate the pregnanolone discriminative stimulus in monkeys. Gaboxadol did not produce pregnanolone-lever responding, further suggesting little or no role for extrasynaptic $\mathrm{GABA}_{\mathrm{A}}$ receptors in the discriminative stimulus effects of pregnanolone. Receptors that have been implicated in the behavioral effects of neuroactive steroids (Maurice et al. 2001; Rupprecht et al. 2001; Dubrovsky 2005), including discriminative stimulus effects of pregnanolone (Engel et al. 2001; Shannon et al. 2005b), 
do not seem to have a prominent role in the pregnanolone discriminative stimulus in monkeys. That is, drugs with actions at NMDA or $\sigma_{1}$ receptors did not produce pregnanolone-lever responding up to doses that decreased rates. While CPBG produced only vehicle-lever responding, suggesting that $5-\mathrm{HT}_{3}$ receptors also do not contribute to the discriminative stimulus effects of pregnanolone, it did not decrease response rates up to the largest dose that could be studied. Thus, in monkeys, positive $\mathrm{GABA}_{\mathrm{A}}$ modulators shared discriminative stimulus effects with pregnanolone and drugs acting at other receptors did not; these results, along with those of other studies (Vanover 1997; 2000; Engel et al. 2001; Shannon et al. 2005a; b; Eppolito et al. 2012), support a primary role of synaptic $\mathrm{GABA}_{\mathrm{A}}$ receptors in the discriminative stimulus effects of pregnanolone.

This role of synaptic $\mathrm{GABA}_{\mathrm{A}}$ receptors is further supported by drug combination studies. Flumazenil, which acts at benzodiazepine sites and has very low efficacy, antagonized the discriminative stimulus effects of benzodiazepines in monkeys discriminating either midazolam or pregnanolone. When shifts in dose-effect curves were compared using Schild analyses, the slope of the straight line fitting these data was not different from unity, suggesting a simple, competitive and reversible interaction. The potency of flumazenil, estimated using $\mathrm{pA}_{2}$ values, was similar in monkeys discriminating pregnanolone and those discriminating midazolam, where $\mathrm{pA}_{2}$ values for flumazenil ranged from 7.41 to 7.69 (Lelas et al. 1999; 2000; Gerak and France 2012). Similarity $\mathrm{pA}_{2}$ values suggests that the same population of synaptic $\mathrm{GABA}_{\mathrm{A}}$ receptors mediates the discriminative stimulus effects of midazolam (Lelas et al. 2000; Gerak and France 2012) and those of pregnanolone (current study) in rhesus monkeys.

Competition between flumazenil and benzodiazepines for benzodiazepine sites results in attenuation of the effects of benzodiazepines (current study; Lelas et al. 1999; 2000; Gerak and France 2012). In contrast, neuroactive steroids act a distinct site (i.e., the interaction between flumazenil and neuroactive steroids is not competitive); consequently, flumazenil would not be expected to antagonize the discriminative stimulus effects of pregnanolone. In monkeys discriminating pregnanolone, doses of flumazenil that shifted benzodiazepine dose-effect curves rightward did not shift the pregnanolone dose-effect curve. Similarly, flumazenil also did not attenuate the effects of pregnanolone in monkeys discriminating midazolam (Gerak and France 2011; 2012). However, in those same animals, flumazenil enhanced the effects of neuroactive steroids, shifting dose-effect curves significantly leftward (Gerak and France 2011; 2012; McMahon and France 2005) due to its low positive modulatory effects at benzodiazepine sites (Dantzer and Pério 1982); if the effects of flumazenil are the same in the two groups, then a similar increase in the potency of neuroactive steroids would be expected in monkeys discriminating pregnanolone. In the current study, flumazenil did not enhance the discriminative stimulus effects of neuroactive steroids. This small difference between the two procedures does not appear to reflect weaker stimulus control for one discriminative stimulus. Time to acquisition of stimulus control cannot be easily compared across groups because training conditions were slightly different across monkeys discriminating pregnanolone early in training; however, the two discriminations were equally robust and stable over time with both groups tested with the same frequency. These results also indicate that the differences in training across monkeys discriminating pregnanolone did not have lingering effects. In addition, the potency and effectiveness of benzodiazepines and pregnanolone were similar in the two groups; midazolam and flunitrazepam were equipotent with pregnanolone 20-fold less potent. Drugs acting primarily at non-GABA $\mathrm{A}_{\mathrm{A}}$ receptors did not produce responding on either the pregnanolone or midazolam lever. Antagonism of the discriminative stimulus effects of benzodiazepines by flumazenil was similar, with comparable $\mathrm{pA}_{2}$ values indicating that the same population of $\mathrm{GABA}_{\mathrm{A}}$ receptors is involved. Thus, the pregnanolone and midazolam discriminative stimuli appear to be very similar despite the ability of flumazenil to enhance 
the discriminative stimulus effects of pregnanolone in monkeys discriminating midazolam and not in those discriminating pregnanolone.

One possible explanation for differential effects of flumazenil across the two groups involves actions of pregnanolone at extrasynaptic $\mathrm{GABA}_{\mathrm{A}}$ receptors. Similarities in the effects of benzodiazepines and neuroactive steroids demonstrate the importance of synaptic $\mathrm{GABA}_{\mathrm{A}}$ receptors in the pregnanolone discriminative stimulus, although extrasynaptic $\mathrm{GABA}_{\mathrm{A}}$ receptors might still play a role. Some extrasynaptic $\mathrm{GABA}_{\mathrm{A}}$ receptors contain a4 or a6 subunits. Flumazenil, but not benzodiazepines, binds to $\mathrm{GABA}_{\mathrm{A}}$ receptors containing these a subunits; however, the manner in which flumazenil interacts with these receptors (positive, neutral or negative modulation) is not known. The ability of flumazenil to enhance the discriminative stimulus effects of neuroactive steroids in monkeys discriminating midazolam and not in monkeys discriminating pregnanolone could be due to interactions between flumazenil and neuroactive steroids at extrasynaptic GABAA receptors. If so, actions at extrasynaptic $\mathrm{GABA}_{\mathrm{A}}$ receptors might account for differences between benzodiazepines and neuroactive steroids.

The current study established pregnanolone as a discriminative stimulus in rhesus monkeys, which has not been reported previously, and demonstrated the importance of synaptic $\mathrm{GABA}_{\mathrm{A}}$ receptors in the discriminative stimulus effects of pregnanolone by showing that benzodiazepines and neuroactive steroids produce remarkably similar effects in monkeys discriminating pregnanolone and those discriminating midazolam. Such similarities in the behavioral effects of neuroactive steroids and benzodiazepines support the therapeutic use of neuroactive steroids, either in addition to or in place of benzodiazepines (Morrow 2007). The qualitative difference in the interaction between flumazenil and pregnanolone depending on the training drug might be indicative of a subtle difference in the behavioral effects of benzodiazepines and neuroactive steroids, which could provide a therapeutic advantage by reducing the incidence of adverse effects (e.g., tolerance).

\section{Acknowledgments}

The authors wish to thank T. Andrews, B. Blaylock, B. Harrington, A. Hernandez, Victoria Hill, Victoria Le, J. Pressly and S. Schirmer for their excellent technical assistance.

These studies were supported by the National Institutes of Health National Institute on Drug Abuse [Grant DA009157] and a Senior Scientist Award to CPF [Grant K05 DA17918]. The content is solely the responsibility of the authors and does not necessarily represent the official views of the National Institute on Drug Abuse or the National Institutes of Health.

\section{References}

Arunlakshana O, Schild HO. Some quantitative uses of drug antagonists. Br J Pharmacol. 1959; $14: 48-58$.

Ator NA. Drug discrimination and drug stimulus generalization with anxiolytics. Drug Dev Res. 1990; 20:189-204.

Ator NA, Grant KA, Purdy RH, Paul SM, Griffiths RR. Drug discrimination analysis of endogenous neuroactive steroids in rats. Eur J Pharmacol. 1993; 241:237-243. [PubMed: 7902289]

Ator NA. High-dose discrimination training with midazolam: context determines generalization profile. Pharmacol Biochem Behav. 1999; 64:237-243. [PubMed: 10515297]

Ator NA. Selectivity in generalization to GABAergic drugs in midazolam-trained baboons. Pharmacol Biochem Behav. 2003; 75:435-445. [PubMed: 12873636]

Bai X, Gerak LR. Comparing the discriminative stimuli produced by either the neuroactive steroid pregnanolone or the benzodiazepine midazolam in rats. Psychopharmacology. 2011; 214:427-435. [PubMed: 20972551] 
Dantzer R, Pério A. Behavioural evidence for partial agonist properties of RO 15-1788, a benzodiazepine receptor antagonist. Eur J Pharmacol. 1982; 81:655-658. [PubMed: 6811297]

de la Garza R, Johanson CE. Discriminative stimulus properties of intragastrically administered damphetamine and pentobarbital in rhesus monkeys. J Pharmacol Exp Ther. 1987; 243:955-962. [PubMed: 2891839]

Dubrovsky BO. Steroids, neuroactive steroids and neurosteroids in psychopathology. Prog NeuroPsychopharmacol Biol Psych. 2005; 29:169-192.

Engel SR, Purdy RH, Grant KA. Characterization of discriminative stimulus effects of the neuroactive steroid pregnanolone. J Pharmacol Exp Ther. 2001; 297:489-495. [PubMed: 11303034]

Eppolito AK, Gerak LR. Tolerance to the rate-increasing and not rate-decreasing effects of pregnanolone in rats. Behav Pharmacol. 2010; 21:736-744.

Eppolito AK, Bai X, Gerak LR. Discriminative stimulus effects of pregnanolone in rats: role of training dose in determining mechanism of action. Psychopharmacology. 2012; 223:139-147. [PubMed: 22526532]

Evans SM, Johanson CE. Discriminative stimulus properties of midazolam in the pigeon. J Pharmacol Exp Ther. 1989; 248:29-38. [PubMed: 2563291]

Garcha HS, Rose IC, Stolerman IP. Midazolam cue in rats: Generalization tests with anxiolytic and other drugs. Psychopharmacology. 1985; 87:233-237. [PubMed: 2864715]

Gerak LR, McMahon LR, France CP. Acute cross tolerance to midazolam, and not pentobarbital and pregnanolone, after a single dose of chlordiazepoxide in monkeys discriminating midazolam. Behav Pharmacol. 2008a; 19:796-804. [PubMed: 19020414]

Gerak LR, Winsauer PJ, Moerschbaecher JM. Overlapping, but not identical, discriminative stimulus effects of the neuroactive steroid pregnanolone and ethanol. Pharmacol Biochem Behav. 2008b; 89:473-479. [PubMed: 18328551]

Gerak LR, France CP. Chronic benzodiazepine treatment does not alter interactions between positive $\mathrm{GABA}_{\mathrm{A}}$ modulators and flumazenil or pentylenetetrazole in monkeys. Behav Pharmacol. 2011; 22:49-57. [PubMed: 21516176]

Gerak LR, France CP. Quantitative analyses of antagonism: combinations of midazolam and either flunitrazepam or pregnanolone in rhesus monkeys discriminating midazolam. J Pharmacol Exp Ther. 2012; 340:742-749. [PubMed: 22173893]

Gonsalves SF, Gallagher DW. Time course for development of anticonvulsant tolerance and GABAergic subsensitivity after chronic diazepam. Brain Res. 1987; 405:94-99. [PubMed: 3567600]

Hosie AM, Wilkins ME, da Silva HM, Smart TG. Endogenous neurosteroids regulate GABA A receptors through two discrete transmembrane sites. Nature. 2006; 444:486-489. [PubMed: 17108970]

Kenakin, T. Pharmacologic analysis of drug-receptor interaction. 2nd ed.. New York: Raven Press; 1993.

Koek W, Assié MB, Zernig G, France CP. In vivo estimates of efficacy at 5-HT 1 A receptors: effects of EEDQ on the ability of agonists to produce lower-lip retraction in rats. Psychopharmacology. 2000; 149:377-387. [PubMed: 10867965]

Kokate TG, Svensson BE, Rogawski MA. Anticonvulsant activity of neurosteroids: correlation with gamma-aminobutyric acid-evoked chloride current potentiation. J Pharmacol Exp Ther. 1994; 270:1223-1229. [PubMed: 7932175]

Kokate TG, Yamaguchi S, Pannell LK, Rajamani U, Carroll DM, Grossman AB, Rogawski MA. Lack of anticonvulsant tolerance to the neuroactive steroid pregnanolone in mice. J Pharmacol Exp Ther. 1998; 287:553-558. [PubMed: 9808680]

Korpi ER, Sinkkonen ST. GABA A receptors subtypes as targets for neuropsychiatric drug development. Pharmacol Ther. 2006; 109:12-32. [PubMed: 15996746]

Lancel M. Role of $\mathrm{GABA}_{\mathrm{A}}$ receptors in the regulation of sleep: initial sleep responses to peripherally administered modulators and agonists. Sleep. 1999; 22:33-42. [PubMed: 9989364]

Lelas S, Gerak LR, France CP. Discriminative-stimulus effects of triazolam and midazolam in rhesus monkeys. Behav Pharmacol. 1999; 10:39-50. [PubMed: 10780301] 
Lelas S, Gerak LR, France CP. Antagonism of the discriminative stimulus effects of positive $\gamma$ aminobutyric acid $_{\mathrm{A}}$ modulators in rhesus monkeys discriminating midazolam. J Pharmacol Exp Ther. 2000; 294:902-908. [PubMed: 10945839]

Löscher W, Rundfeldt C, Hönack D, Ebert U. Long-term studies on anticonvulsant tolerance and withdrawal characteristics of benzodiazepine receptor ligands in different seizure models in mice. I. Comparison of diazepam, clonazepam, clobazam and abecarnil. J Pharmacol Exp Ther. 1996; 279:561-572. [PubMed: 8930158]

Maurice T, Urani A, Phan VL, Romieu P. The interaction between neuroactive steroids and the sigma 1 receptor function: behavioral consequences and therapeutic opportunities. Brain Res Brain Res Rev. 2001; 37:116-132. [PubMed: 11744080]

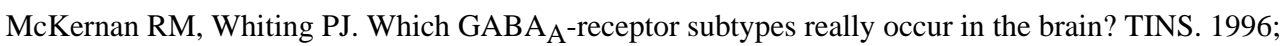
19:139-143. [PubMed: 8658597]

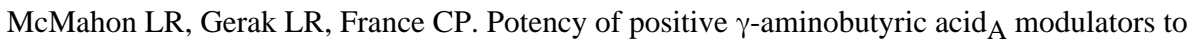
substitute for a midazolam discriminative stimulus in untreated monkeys does not predict potency to attenuate a flumazenil discriminative stimulus in diazepam-treated monkeys. J Pharmacol Exp Ther. 2001; 298:1227-1235. [PubMed: 11504825]

McMahon LR, France CP. Acute and chronic effects of the neuroactive steroid pregnanolone on schedule-controlled responding in rhesus monkeys. Behav Pharmacol. 2002a; 13:545-555. [PubMed: 12409993]

McMahon LR, France CP. Daily treatment with diazepam differentially modifies sensitivity to the effects of $\gamma$-aminobutyric acid $_{A}$ modulators on schedule-controlled responding in rhesus monkeys. J Pharmacol Exp Ther. 2002b; 300:1017-1025. [PubMed: 11861811]

McMahon LR, France CP. Combined discriminative stimulus effects of midazolam with other positive $\mathrm{GABA}_{\mathrm{A}}$ modulators and $\mathrm{GABA}_{\mathrm{A}}$ receptor agonists in rhesus monkeys. Psychopharmacology. 2005; 178:400-409. [PubMed: 15765255]

Morrow AL. Recent developments in the significance and therapeutic relevance of neuroactive steroids-Introduction to the special issue. Pharmacol Ther. 2007; 116:1-6. [PubMed: 17531324]

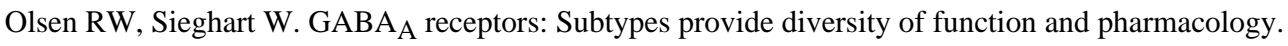
Neuropharmacology. 2009; 56:141-148. [PubMed: 18760291]

Olsen RW, Hanchar HJ, Meera P, Wallner M. GABA A receptor subtypes: the "one glass of wine" receptors. Alcohol. 2007; 41:201-209. [PubMed: 17591543]

Reddy DS, Rogawski MA. Chronic treatment with the neuroactive steroid ganaxolone in the rat induces anticonvulsant tolerance to diazepam but not to itself. J Pharmacol Exp Ther. 2000; 295:1241-1248. [PubMed: 11082461]

Reddy DS, Rogawski MA. Enhanced anticonvulsant activity of neuroactive steroids in a rat model of catamenial epilepsy. Epilepsia. 2001; 42:337-344. [PubMed: 11442150]

Rowlett JK, Winger G, Carter RB, Wood PL, Woods JH, Woolverton WL. Reinforcing and discriminative stimulus effects of the neuroactive steroids pregnanolone and Co 8-7071 in rhesus monkeys. Psychopharmacology. 1999; 145:205-212. [PubMed: 10463322]

Rupprecht R, di Michele F, Hermann B, Strohle A, Lancel M, Romeo E, Holsboer F. Neuroactive steroids: molecular mechanisms of action and implications for neuropsychopharmacology. Brain Res. 2001; 37:59-67.

Shannon EE, Porcu P, Purdy RH, Grant KA. Characterization of the discriminative stimulus effects of the neuroactive steroid pregnanolone in DBA/2J and C57BL/6J inbred mice. J Pharmacol Exp Ther. 2005a; 314:675-685. [PubMed: 15857945]

Shannon EE, Purdy RG, Grant KA. Discriminative stimulus effects of $5.6 \mathrm{mg} / \mathrm{kg}$ of pregnanolone in DBA/2J and C57BL/6J inbred mice. Alcohol. 2005b; 32:35-45. [PubMed: 16472717]

Spealman RD. Discriminative stimulus effects of midazolam in squirrel monkeys: Comparison with other drugs and antagonism by Ro 15-1788. J Pharmacol Exp Ther. 1985; 235:456-462. [PubMed: 2932547]

Vanover KE. Discriminative stimulus effects of the endogenous neuroactive steroid pregnanolone. Eur J Pharmacol. 1997; 327:97-101. [PubMed: 9200546]

Vanover KE, Suruki M, Robledo S, Huber M, Wieland S, Lan NC, Gee KW, Wood PL, Carter RB. Positive allosteric modulators of the $\mathrm{GABA}_{\mathrm{A}}$ receptor: differential interaction of benzodiazepines 
and neuroactive steroids with ethanol. Psychopharmacology. 1999; 141:77-82. [PubMed: 9952068]

Vanover KE. Effects of benzodiazepine receptor ligands and ethanol in rats trained to discriminate pregnanolone. Pharmacol Biochem Behav. 2000; 67:483-487. [PubMed: 11164076]

Wafford KA. GABA A receptor subtypes: any clues to the mechanism of benzodiazepine dependence? Curr Opin Pharmacol. 2005; 5:47-52. [PubMed: 15661625]

Wieland S, Belluzzi J, Hawkinson JE, Hogenkamp D, Upasani R, Stein L, Wood PL, Gee KW, Lan NC. Anxiolytic and anticonvulsant activity of a synthetic neuroactive steroid Co 3-0593.

Psychopharmacology. 1997; 134:46-54. [PubMed: 9399366]

Woudenberg F, Slangen JL. Discriminative stimulus properties of midazolam: Comparison with other benzodiazepines. Psychopharmacology. 1989; 97:466-470. [PubMed: 2567029] 

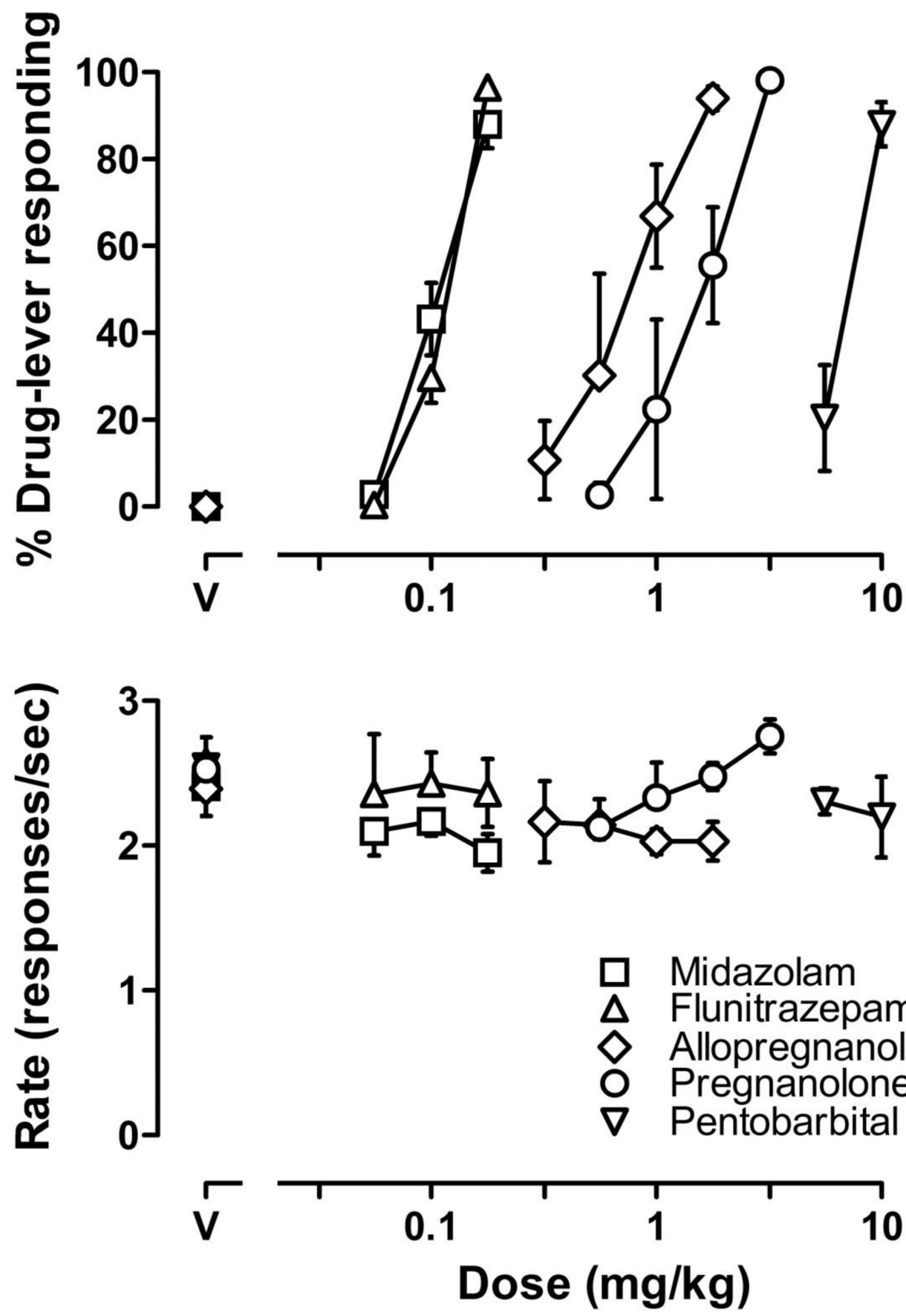

Figure 1.

Discriminative stimulus effects of positive $\mathrm{GABA}_{\mathrm{A}}$ modulators and their effects on response rate in monkeys discriminating pregnanolone. Each curve was determined twice in 4 monkeys. Abscissae: cumulative dose in milligrams per kilogram body weight. Data above $\mathrm{V}$ represent the effects of vehicle 15 min thereafter. Ordinate, upper panel: mean ( \pm 1 SEM) percentage of total responding that occurred on the pregnanolone-appropriate lever; lower panel: rate (responses/sec $\pm 1 \mathrm{SEM}$ ). 

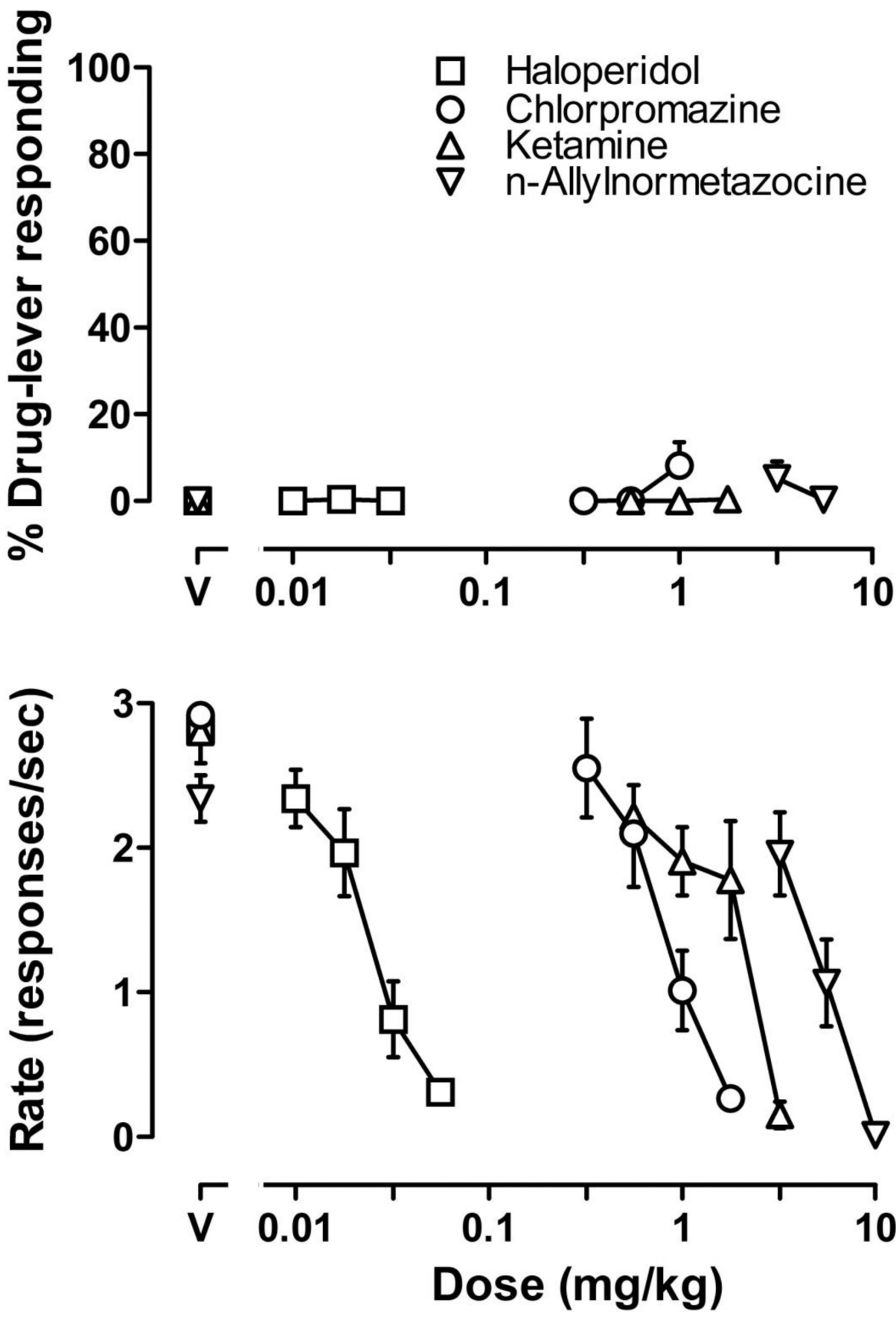

Figure 2.

Discriminative stimulus and rate-decreasing effects of drugs whose primary mechanism of action is not at $\mathrm{GABA}_{\mathrm{A}}$ receptors in monkeys discriminating pregnanolone. Each curve was determined twice in 4 monkeys. Abscissae: cumulative dose in milligrams per kilogram body weight. Data above V represent the effects of vehicle given on the first cycle with cumulative doses of drug given every 15 min thereafter. Ordinate, upper panel: mean $( \pm 1$ SEM) percentage of total responding that occurred on the pregnanolone-appropriate lever; lower panel: rate (responses/sec $\pm 1 \mathrm{SEM}$ ). 

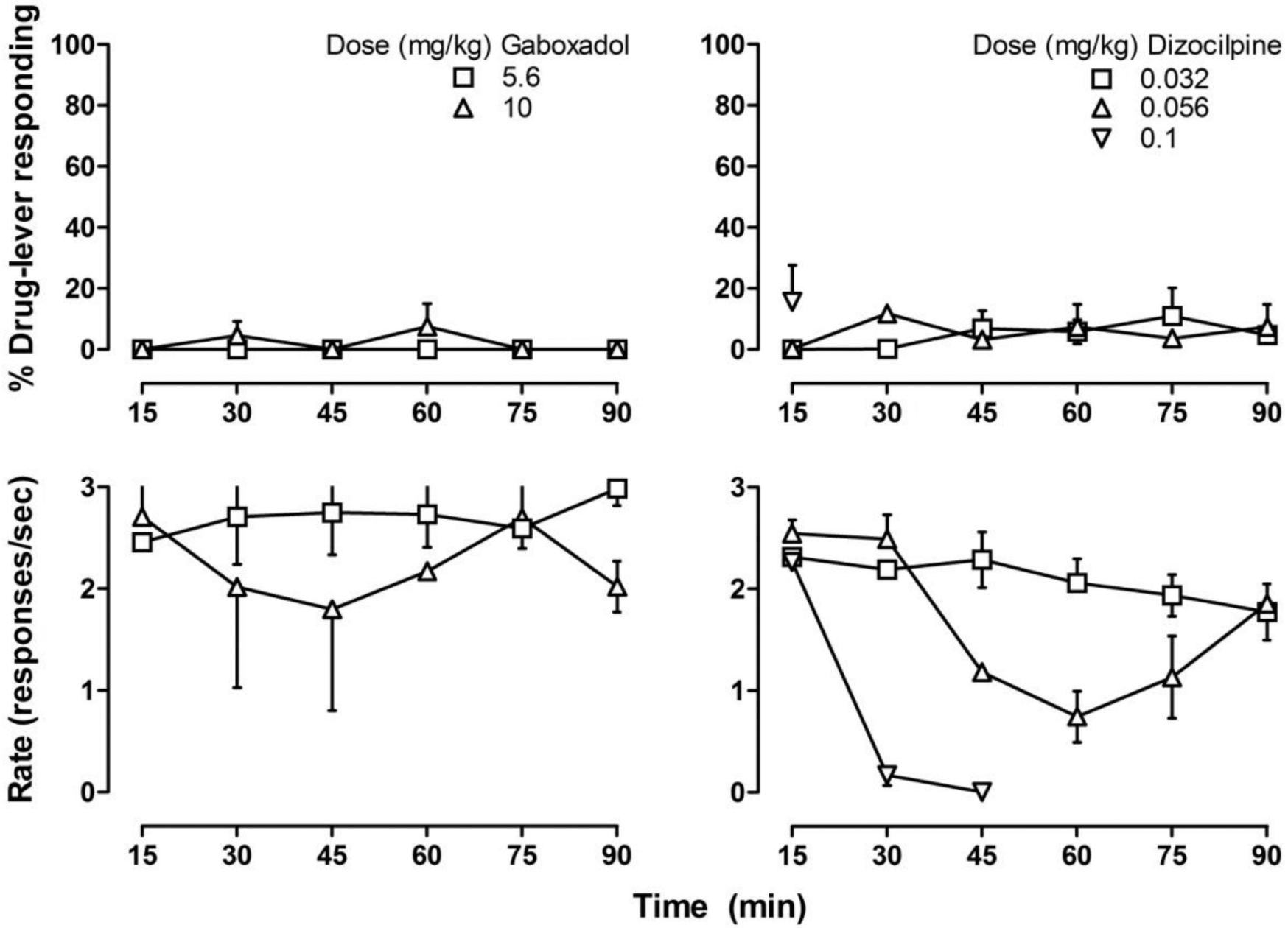

Figure 3.

Discriminative stimulus and rate-decreasing effects of gaboxadol and dizocilpine in monkeys discriminating pregnanolone. Because of the long onset of these drugs, the effects of each dose of gaboxadol and dizocilpine were monitored over 90-min sessions with each dose studied twice in 4 monkeys. Abscissae: time (min) since administration of gaboxadol (left panels) or dizocilpine (right panels). Ordinate, upper panel: mean ( \pm 1 SEM) percentage of total responding that occurred on the pregnanolone-appropriate lever; lower panel: rate (responses/sec $\pm 1 \mathrm{SEM}$ ). 


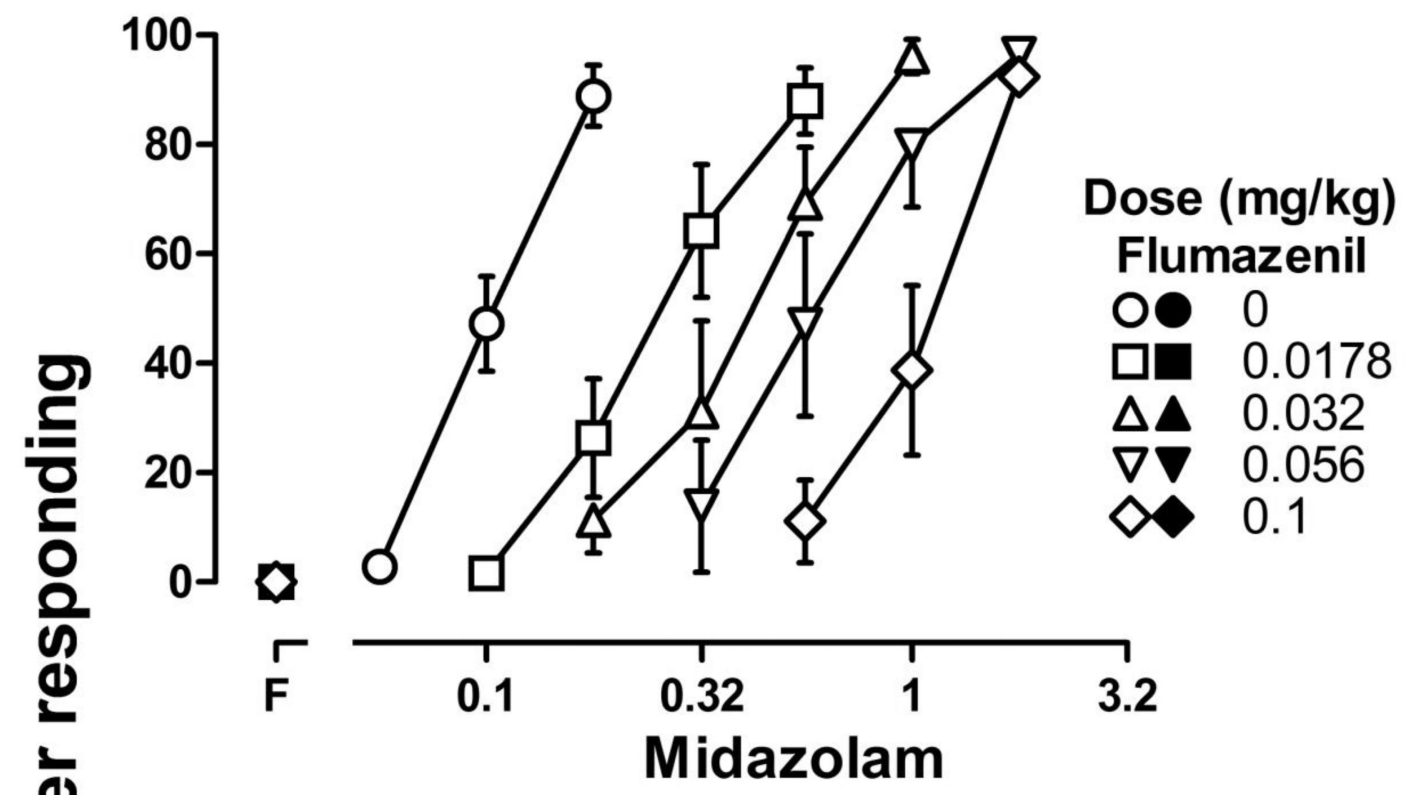

임

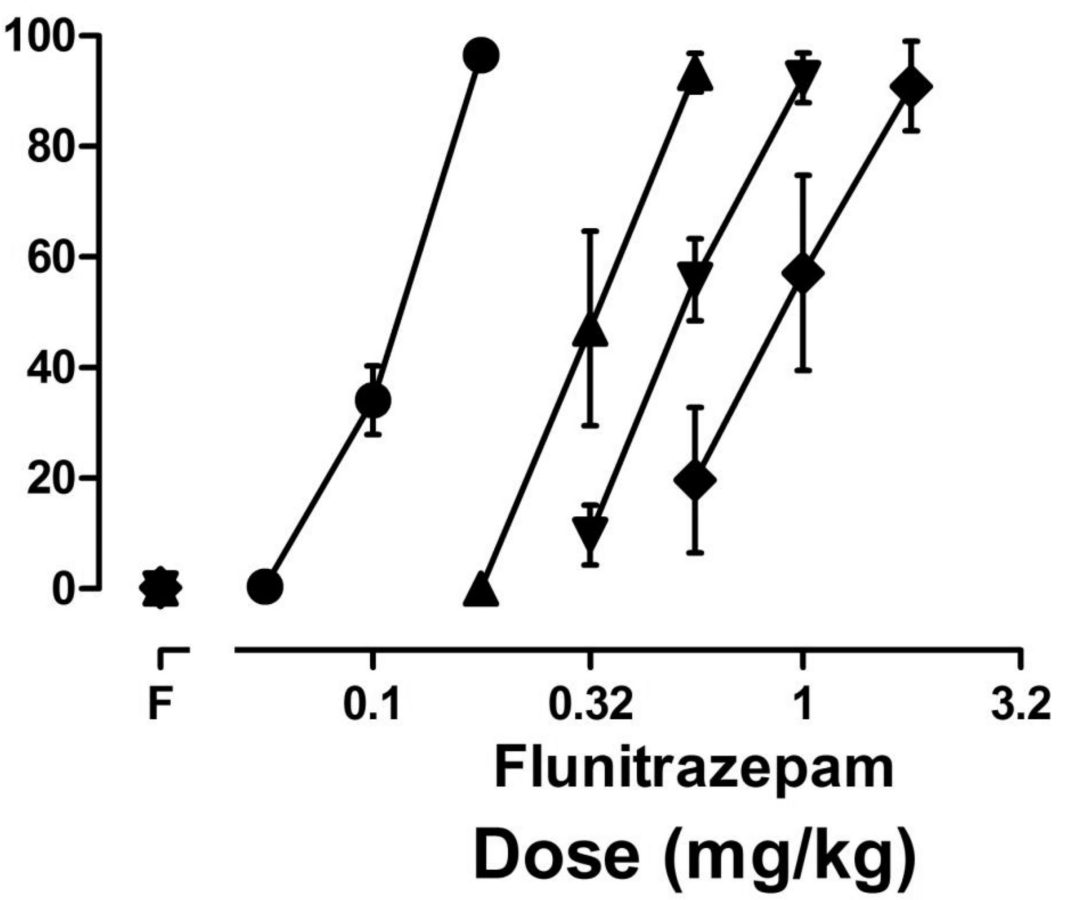

Figure 4.

Discriminative stimulus effects of midazolam (upper panel) and flunitrazepam (lower panel) given alone (circles) or after various doses of flumazenil in monkeys discriminating pregnanolone. Each curve was determined twice in 4 monkeys. Abscissae: cumulative dose in milligrams per kilogram body weight; data above F represent the effects of flumazenil given on the first cycle with cumulative doses of the benzodiazepine given every $15 \mathrm{~min}$ thereafter. Ordinates: mean $( \pm 1$ SEM) percentage of total responding that occurred on the pregnanolone-appropriate lever. 

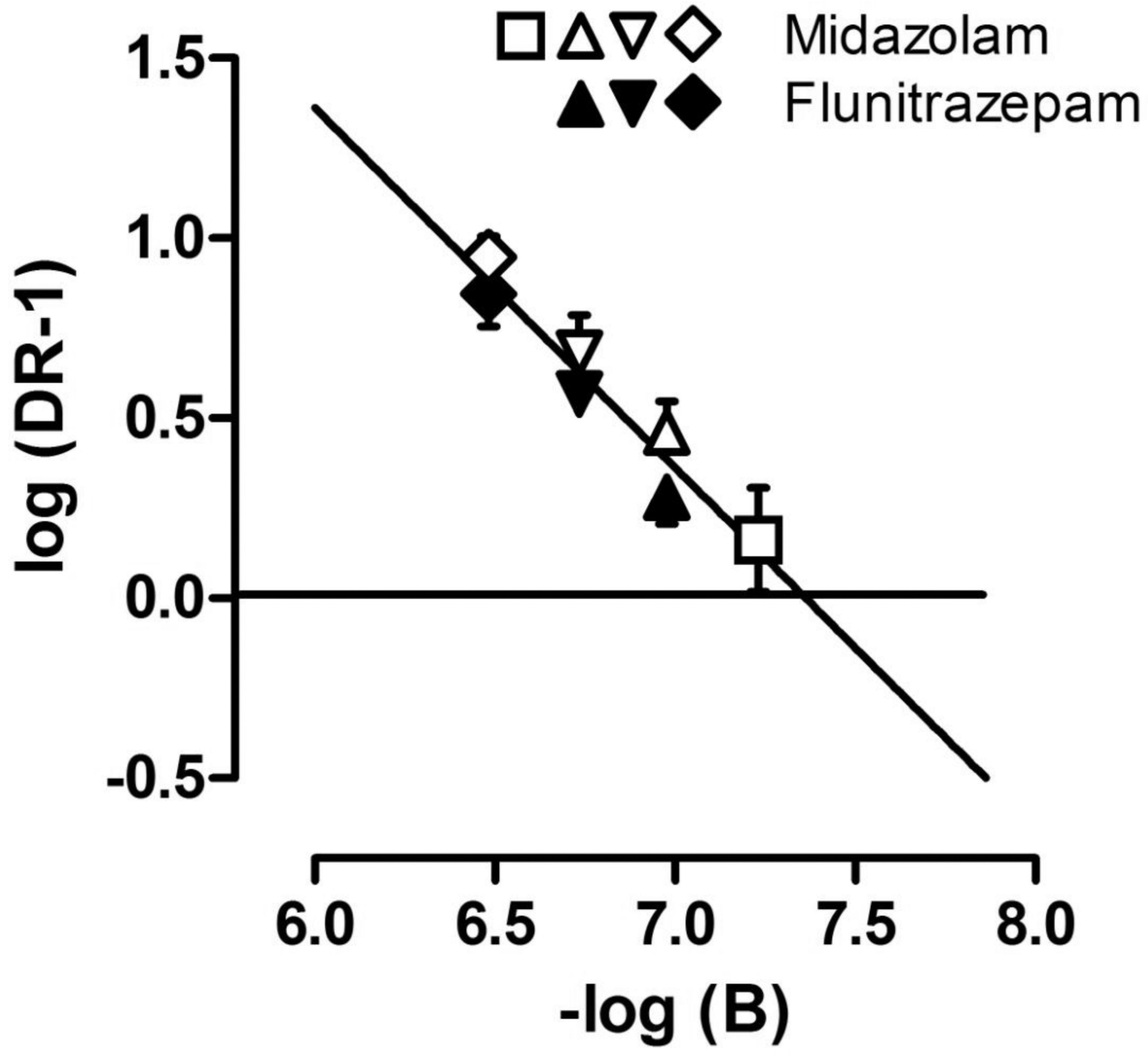

Figure 5.

Schild plot for flumazenil studied with midazolam and flunitrazepam. Raw data are shown in Figure 4 and symbols match those used in Figure 4. Abscissa: negative log of the molar dose of flumazenil. Ordinate: $\log$ (dose-ratio - 1). 


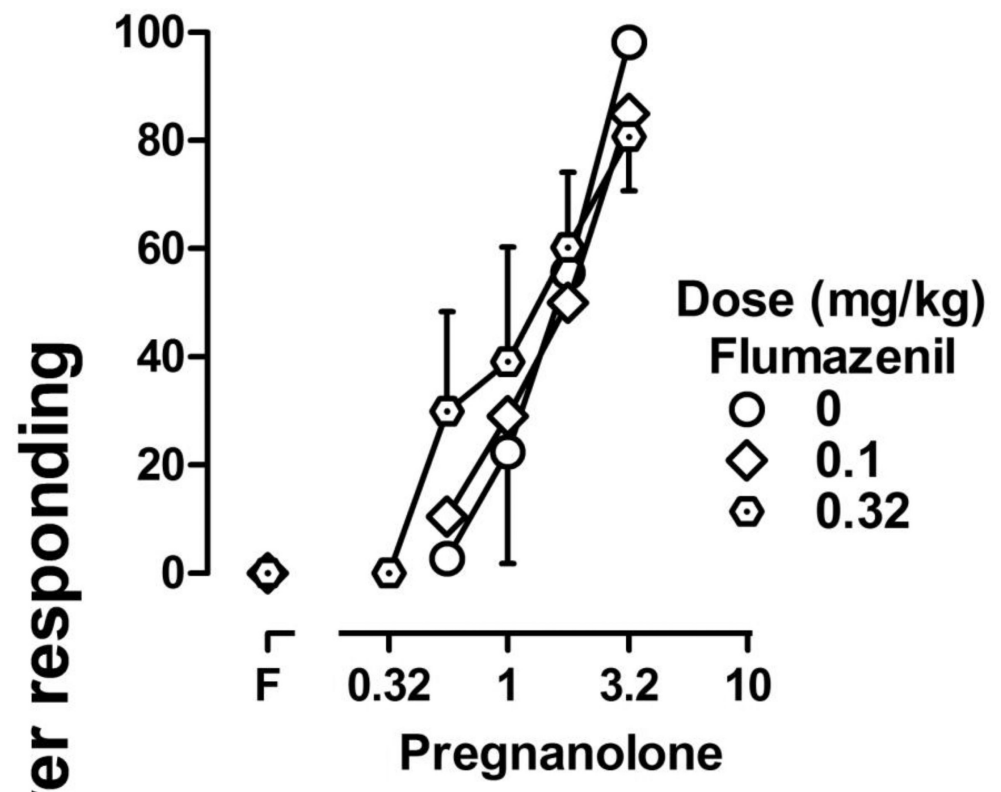

త
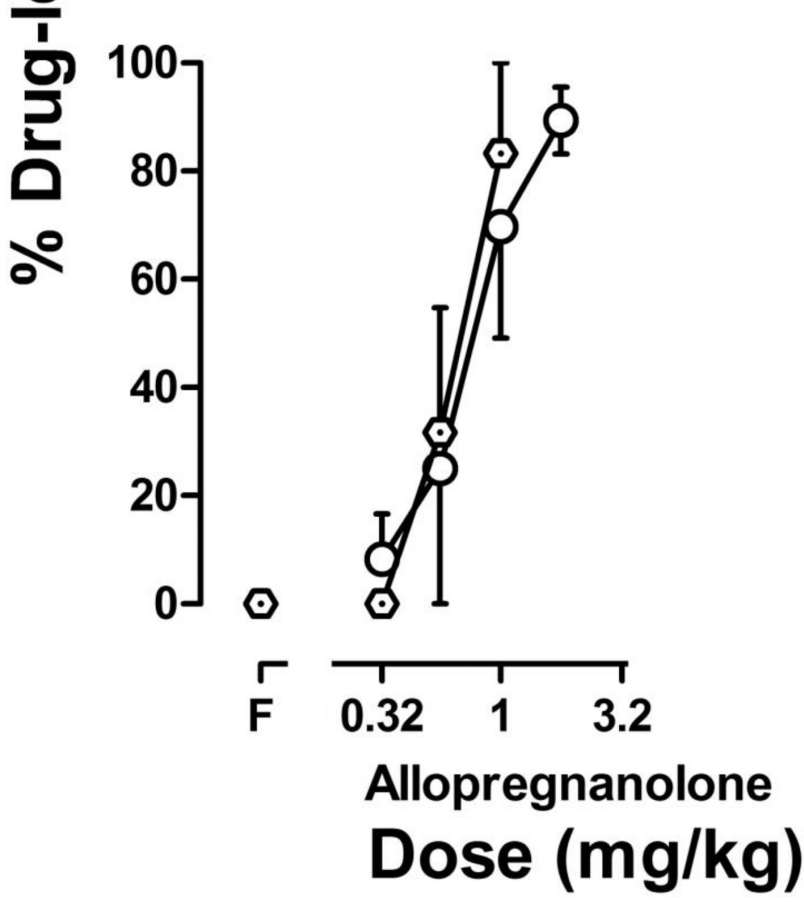

Figure 6.

Discriminative stimulus effects of pregnanolone (upper panel) and allopregnanolone (lower panel) given alone (circles) or after various doses of flumazenil in monkeys discriminating pregnanolone. Each curve was determined twice in 4 monkeys. Abscissa: cumulative dose in milligrams per kilogram body weight; data above F represent the effects of flumazenil given on the first cycle with cumulative doses of the neuroactive steroid given every 15 min thereafter. Ordinate: mean $( \pm 1$ SEM) percentage of total responding that occurred on the pregnanolone-appropriate lever. 


\section{Table 1}

Slopes of Schild plots and $\mathrm{pA}_{2}$ values (95\% confidence limits) for flumazenil with midazolam and with flunitrazepam determined with constrained and unconstrained slopes.

\begin{tabular}{|c|c|c|c|}
\hline & $\begin{array}{c}\text { Slope } \\
\text { (unconstrained) }\end{array}$ & $\begin{array}{c}\mathbf{p A}_{\mathbf{2}} \\
\text { (unconstrained) }\end{array}$ & $\begin{array}{c}\mathbf{p A}_{\mathbf{2}} \\
(\text { constrained) }\end{array}$ \\
\hline Midazolam & $-1.03(-1.40,-0.66)$ & $7.37(7.21,7.69)$ & $7.39(7.30,7.49)$ \\
\hline Flunitrazepam & $-1.14(-1.57,-0.71)$ & $7.25(7.09,7.58)$ & $7.32(7.24,7.40)$ \\
\hline
\end{tabular}

